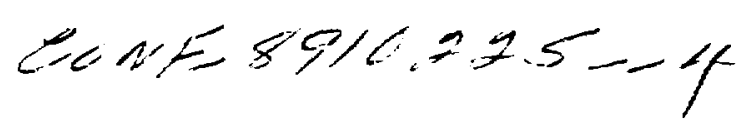

"The submitted m'nuscript has been authored by a ccatractor of the U.S. Government under contract DE-ACOS$840 R 21400$. Accordingly, the U.S. Government retains a nonex slusive. royalty-free license to publish or reproduce the published form of this

contribution, or allow others 10 do so, for CONF-8910225--4

DE90 001959

\title{
EXPERIMENTAL EVIDENCE OF INCREASED ELECTRON TEMPERATURE, PLASMA POTENTIAL, AND ION ENERGY NEAR AN ICRF ANTENNA FARADAY SHIELD*
}

\author{
J. B. O. Caughman, II \\ D. N. Ruzic \\ University of Illinois, Urbana-Champaign \\ D. J. Hoffman \\ Oak Ridge National Laboratory
}

\begin{abstract}
DISCLAIMER
This report was prepared as an account of work sponsored by an agency of the United States Government. Neither the United States Government nor any agency thereof, nor any of their employees, makes any warranty, express or implied, or assumes any legal liability or responsibility for the accuracy, completeness, or usefulness of any information, apparatus, product, or process disclosed, or represents that its use would not infringe privately owneri rights. Reference herein to any specific commercial product, process, or service by trade natne, trademark, manufacturer, or otherwise does not necessarily constitute or imply its endorsement, recommendation, or favoring by the United States Government or any agency thereof. The views and opinions of authors expressed herein do not necessarily state or reflect those of the United States Government or any agency thereof.
\end{abstract}

* Research supported by the Magnetic Fusion Energy Technology Fellowship program, administered by Oak Ridge Associated Universities for the U.S. Department of Energy, and by the Office of Fusion Energy, U.S. Department of Energy, under contract DE-AC05-84OR21400 and subcontract 19X-SB359V with Martin Marietta Energy Systems, Inc. 
EXPERIMENTAL EVIDENCE OF INCREASED ELECTRON TEMPERATLRE, PLASMA POTENTIAL, AND ION ENERGY NEAR AN ICRF ANTENNA FARADAY SHIELD

J. B. O. Caughman II and D. N. Ruzic, University of Illinois

D. J. Hoffman, Oak Ridge National Laboratory

\section{ABSTRACT}

Plasma properties and ion energies have been measured near the surface of the Faraday shield for an ICRF antenna to determine the effect of if fields on the energy of ions bombarding the shield surface. A resonant loop antenna with a two-tier Faraday shield was used on the RF Test Facility at Oak Ridge National Laboratory. The ECH plasma was produced by a 10.6 GHz klystron and had a central density of $\sim 10^{11} \mathrm{~cm}^{-3}$ and an electron temperature of 5-10 eV. The static magnetic field at the antenna was $\sim 2$ kG. A capacitive probe was used to measure the time-varying floating potential and a Langmuir probe was used to measure the time-averaged electron temperature, density, and dc floating potential. Both probes were scanned in front of the antenna. Ion energies were measured with a gridded energy analyzer located next to the antenna. The time-varying floating potential followed the magnetic field pattern of the antenna, indicating that the electromagnetic field is responsible for the potential formation. Potential values of $300 \mathrm{~V}$ p-p have been measured. Electron temperatures increased with if power and reached values $\geq 60 \mathrm{eV}$ for an $\mathrm{rf}$ power of $\sim 25 \mathrm{~kW}$. The energy of ions hitting a grounded surface also increased with rf power and exceeded $300 \mathrm{eV}$ at $\sim 25 \mathrm{~kW}$ of rf power (compared with energies of $5-15 \mathrm{eV}$ with no rf power). The increase in ion energy can be at least partially explained by 
an increase in the sheath potential, which in turn is caused by an increase in the electron temperature.

\section{INTRODUCTION}

Experiments on several confinement devices have shown an increase in the impurity concentration in the plasma during ICRF heating. Specifically, the Faraday shield of the activated antenna has been identified as a local impurity source. However, the processes taking place at the antenna that cause the impurity generation have not been identified. One area that needs to be addressed in understanding the impurity generation is the role of the plasma sheath that forms on the material boundaries in contact with the plasma. The magnitude and form of the plasma potential in front of the antenna must be known to determine the effect of this potential on the energy of the ions hitting the shield. The effect of the electron temperature and the rf fields on the potential formation in front of the antenna must be determined.

Plasma parameters and ion energies have been measured near an ICRF antenna Faraday shield in an experiment conducted on the RF Test Facility (RFTF) at Oak Ridge National Laboratory. The antenna used was a single-strap resonant loop antenna with a two-tier Faraday shield, shown in Fig. 1. The antenna was operated at $42 \mathrm{MHz}$, and the rf power was varied up to $60 \mathrm{~kW}$. The RFTF plasma was made by an ECH discharge using a 10.6 $\mathrm{GHz}$ klystron with a power of $\sim 17 \mathrm{~kW}$. Hydrogen was used as the operating gas for most of the experiments at pressures ranging from $1 \times 10^{-4}$ to $4 \times$ $10^{-4}$ Torr. The electron temperature at the antenna was 5-10 eV, and the electron density was $\sim 5 \times 10^{10} \mathrm{~cm}^{-3}$. The magnetic field was $\sim 2 \mathrm{kG}$. 


\section{EXPERIMENT}

The time-rarying floating potential was measured with a capacitively coupled probe that was scanned in front of the antenna. The probe was calibrated at the rf frequency ( $42 \mathrm{MHz}$ ) is described in Ref. [1]. A Langmuir probe was scanned in the same area as the capacitive probe to measure the time-averaged electron temperature, electron density, and floating potential. The probe tips were $\sim 1 \mathrm{~cm}$ from the surface of the Faraday shield. The Langmuir probe was terminated on a small $\mathrm{dc}$ and $\mathrm{rf}$ load and thus measured the time-averaged current as a function of applied probe bias voltage. The electron temperature was then calculated from the lower portion of the $I_{e}$ versus $V_{b i a}$ curve to avoid problems associated with response of a Langmuir probe in a rf plasma [2]. The electron density was calculated by measuring the ion current well into the saturation region and then corrected with the LaFramboise method [3]. The time-averaged floating potential was taken from the time-averaged current measurement and then corrected for self-bias due to $\mathrm{rf}$ [4]. The lower limit of the plasma potential was estimated from the $\ln \left(I_{e}\right)$ versus $\mathrm{V}_{b i a}$, curve, and the time-averaged plasma potential was estimated by adding the value of the rf potential from the capacitive probe measurement to this lower limit [5]. The time-averaged plasma potential was also estimated as being the time-averaged floating potential plus $2.5 T_{e}$ [6]. These two methods for calculating the time-averaged plasma potential generally agreed within $10 \%$.

A gridded energy analyzer was located $\sim 4 \mathrm{~cm}$ below the antenna and measured the distribution of ion energies incident on a grounded surface in a magnetized rf plasma. Since the magnetic field was parallel to the surface and to the biasing grids of the analyzer, the analyzer was thin $(\leq 1 \mathrm{~mm}$ thick) so that the ion energies perpendicular to the magnetic field could be 
measured. The outside of the analyzer and its entrance grid were grounded, so that the energy of the ions accelerated through the sheath that formed on a grounded surface was measured.

\section{RESULTS}

The capacitive probe results indicate that the floating potential oscillates at the rf frequency and can reach values of up to $300 \mathrm{~V} \mathrm{p}$-p for an antenna current of $\sim 400 \mathrm{~A}$. The of floating potential, normalized by the antenna current, is shown in Fig. 2 for gas pressures of $(1-3) \times 10^{-4}$ Torr and for rf powers ranging from 12 to $55 \mathrm{~kW}$. The potentials were normalized by the antenna current to look for any dependence on the rf field strength. The data for an rf power of $\sim 2 \mathrm{~kW}$ showed the same trends. The waveform of the potential was sinusoidal for all cases. For each data set at the same pressure, the data show the trend of being fairly level in the middle of the current strap and decreasing slightly towards the ends of the strap. These potentials follow the magnetic field pattern of the antenna instead of the voltage distribution on the current strap, indicating that the potential formation was due to the electromagnetic fields and not the electrostatic fields.

The normalized potentials were lower at $1 \times 10^{-4}$ Torr and were about the same for pressures of $(2-3) \times 10^{-4}$ Torr. This difference may be due to the capacitance of the rf sheath at the probe tip. The sheath capacitance acts as a series capacitor between the probe tip and the plasma and decreases the coupled signal to the probe tip. The sheath capacitance will increase as the electron density increases because the sheath thickness is smaller, and the coupled signal to the probe tip will increase. The densities were lower for the lower gas pressures, typically ranging from $1 \times 10^{10}$ to $3 \times 10^{10} \mathrm{~cm}^{-3}$ for the $1 \times 10^{-4}$ Torr and increased to $(8-16) \times 10^{10} \mathrm{~cm}^{-3}$ for $4 \times 10^{-4}$ Torr. 
The electron temperature and the time-averaged plasma potential in front of the antenna are shown in Fig. 3 for a gas fill pressure of $2 \times 10^{-4}$ Torr. Also shown are data from below the antenna, close to the energy analyzer. The electron temperature and the plasma potential clearly increase with rf power and antenna current. Electron temperatures without rf were 5-10 eV and increased to $54-60 \mathrm{eV}$ for an of power of $\sim 26 \mathrm{~kW}$ and an antenna current of $\sim 390 \mathrm{~A}$; the average plasma potential without $\mathrm{rf}$ was $7-12 \mathrm{~V}$ and increased to $180-230 \mathrm{~V}$ for these conditions. Both the electron temperature and the average plasma potential were fairly level in front of the antenna, indicating an electromagnetic field dependence.

Without $\mathrm{rf}$, the plasma densities were $3-5 \times 10^{10} \mathrm{~cm}^{-3}$ in front of the antenna and about $7 \times 10^{10} \mathrm{~cm}^{-3}$ below it. The electron density in front of the antenna decreased $\sim 50 \%$ at lower rf power and $25-50 \%$ at higher If power. The density below the antenna decreased $\sim 25 \%$ for the lower If power case and increased $\sim 50 \%$ with higher $\mathrm{r}^{f}$ power. Even though the density increased, the electron temperature and the average plasma potential followed a scaling similar to that of the parameters in front of the antenna. Experiments at $4 \times 10^{-4}$ Torr showed that the temperature and potential scaled with the antenna current in the same way, even though the density in front of the antenna increased $100 \%$ to $150 \%$ for an $\mathrm{rf}$ power of $\sim 11.2$ $k W$. Thus, there was no clear dependence of the electron temperature or the plasma potential on the local electron density.

Energies for ions hitting a grounded surface also increased with rf power and antenna current. The perpendicular ion energy distribution measured with the energy analyzer is shown in Fig. 4 for the three sets of plasma and antenna conditions. The fine structure of the distributions is not meaningful because of the error involved in the measurement. The distributions were 
normalized so that the integral over the energy was one. The ion energy distributions were generally peaked near the time-averaged plasma potential for all the experiments. Energy distributions were peaked at 5-10 eV for the experiments without of and increased with of power. Ions with energies above $300 \mathrm{eV}$ were measured for experiments with an rf power of $\sim 20 \mathrm{~kW}$ and an antenna current of $\sim 400 \mathrm{~A}$. The distributions were clearly shifted to higher energies with the higher rf power and antenna current. The magnitude of the energy shift follows roughly the same scaling as the electron temperature increase, indicating that the electrons caused an increase in the sheath potential. The ions were being accelerated by this sheath into the analyzer.

\section{DISCUSSION}

This experiment was designed to test rf-plasma interactions near the antenna with rf fields and antenna conditions similar to those found in highpower if experiments on confinement devices. The antenna voltages and currents in these experiments were within $\sim 50 \%$ of those that would be expected in a tokamak. For example, at $\sim 25 \mathrm{~kW}$, the peak antenna voltage was $\sim 20 \mathrm{kV}$ and the antenna current was $\sim 500 \mathrm{~A}$. While most of the rf power in a tokamak will be absorbed in the resonance zone, the power and fields must pass through the low-density near-field area of the antenna. The amount of power deposited in the near field is not exactly known, but the power levels absorbed in our experiments are within reason of what would be expected. Some of this power appears to be coupling to the electrons and increasing their energy.

The neutral density and the fractional ionization at the antenna in RFTF were different from those of a tokamak edge environment. The neutral density was higher, although some plasma configurations in tokamaks have 
shown a neutral pressure of up to $1 \mathrm{~m}$ Torr $[7]$. The electron density for the experiments ranged from $0.1 \times 10^{10}$ to $2.0 \times 10^{11} \mathrm{~cm}^{-3}$ compared to densities of $1-5 \times 10^{12} \mathrm{~cm}^{-3}$ at the antenna in tokamaks [8]. The fractional ionization at the antenna ranged from $0.3 \%$ to $2.0 \%$ for these experiments, which is also lower than for a tokamak. Although the neutral density was higher in RFTF, the increase in the electron temperature and the plasma potential cannot be readily explained by an electron-particle interaction. At a neutral pressure of $1 \times 10^{-4}$ Torr $\mathrm{H}_{2}$, the mean free path for an electronneutral collision is $2.8 \mathrm{~m}$ for an $8 \mathrm{eV}$ electron and $8.2 \mathrm{~m}$ for a $40 \mathrm{eV}$ electron [9]. Since the connection length from the antenna in RFTF to the wall is $\sim 0.4 \mathrm{~m}$, an electron is more likely to collide with the wall or the antenna than with a neutral. The electron will experience many if cycles before colliding with a neutral, because the collision frequency will be on the order of 600 $\mathrm{kHz}$ for an $8 \mathrm{eV}$ electron and $460 \mathrm{kHz}$ for a $40 \mathrm{eV}$ electron. Thus, electron heating due to decorrelation collisions with neutrals as the electrons oscillate in the rf field seems unlikely because of the long time between collisions. A Fermi acceleration mechanism, due to the electrons bouncing off an oscillating sheath or the rf parallel electric field, seems more likely because of the faster time scale for the interaction [10].

The electron temperature, plasma potential, and ion energy clearly increase with antenna current and near-field strength. The increase in the ion energies measured with the energy analyzer is consistent with an increased sheath potential resulting from an increase in the electron temperature. These parameters were fairly constant in front of the antenna, indicating that the electromagnetic field was responsible for the increased in potential and temperature. These large potentials, coupled with the acceler- 
ation of the ions through the resulting sheath, will cause an increase in the amount of erosion and impurity generation from the Faraday shield.

\section{ACKNOWLEDGEMENTS}

This research was supported by the Magnetic Fusion Energy Technology Fellowship Program administered by Oak Ridge Associated Universities for the U.S. Department of Energy and by the Office of Fusion Energy, U.S. Department of Energy under contract DE-AC05-840R21400 and subcontract 19X-SB359V with Martin Marietta Energy Systems, Inc.

\section{REFERENCES}

[1] J. B. O. Caughman, II, D. N. Ruzic, and D. J. Hoffman, J. Vac. Sci. Technol. A 7 (1989) 1092-1098.

[2] N. Hershkowitz, M. H. Cho, C. H. Nam, and T. Intrator, Plasma Chem. Plasma Process., 8 (1988) 35.

[3] P. M. Chung, L. Talbot, and K. J. Touryan, Electric Probes in Stationary and Flowing Plasmas: Theory and Application (Springer-Verlag, New York, 1975).

[4] A. Boschi and F. Magtistrelli, Nuovo Cimento, 29 (1963) 487-499.

[5] J. B. O. Caughman, II, Ph.D. thesis, University of Illinois at UrbanaChampaign, October 1989.

[6] A. B. DeWald, A. W. Bailey, and J. N. Brooks, Phys. Fluids, 30 (1987) 267.

[7] J. S. deGrassie et al., J. Vac. Sci. Technol., 10 (1982) 527.

[8] M. Burěs et al., Plasma Phys. Controlled. Fusion, 30 (1988) 149-167.

[9] C. F. Barnett et al, Atomic Data For Controlled Fusion Research, ORNL-5207, Oak Ridge National Laboratory, February 1977, p. C.1.4. 
[10] M. D. Carter, D. B. Batchelor, and E. F. Jaeger, these proceedings.

\section{FIGURE CAPTIONS}

Fig. 1. Front view and sectional view of the resonant loop antenna showing the position of the probes relative to the Faraday shield.

Fig. 2. The If component of the floating potential normalized by the antenna current.

Fig. 3. Electron temperature and average plasma potential in front of the antenna for a gas pressure of $2 \times 10^{-4}$ Torr.

Fig. 4. Measured perpendicular ion energy distributions for the indicated if powers and antenna currents for a gas pressure of $2 \times 10^{-4}$ Torr. 


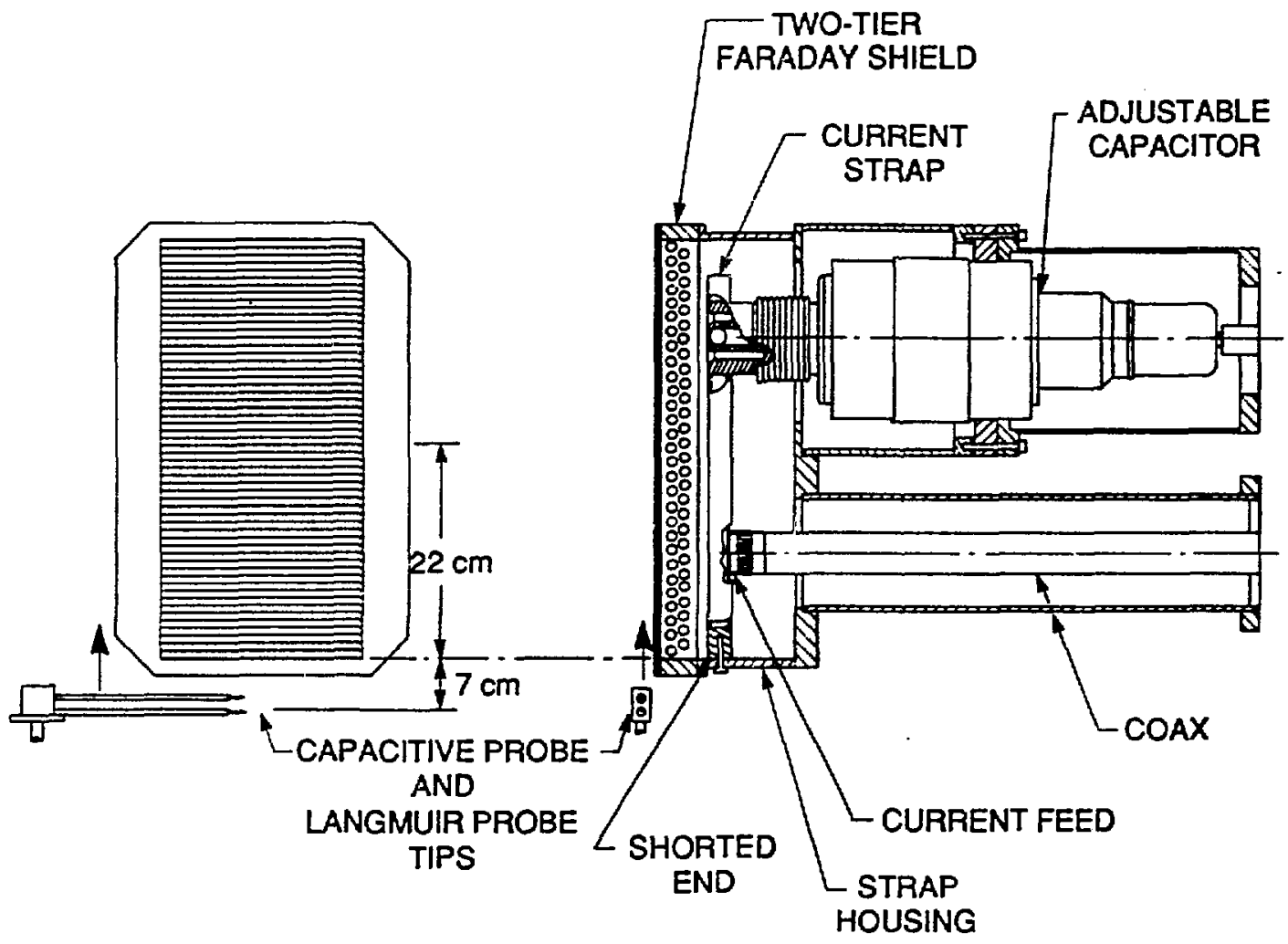

Fig. 1. 


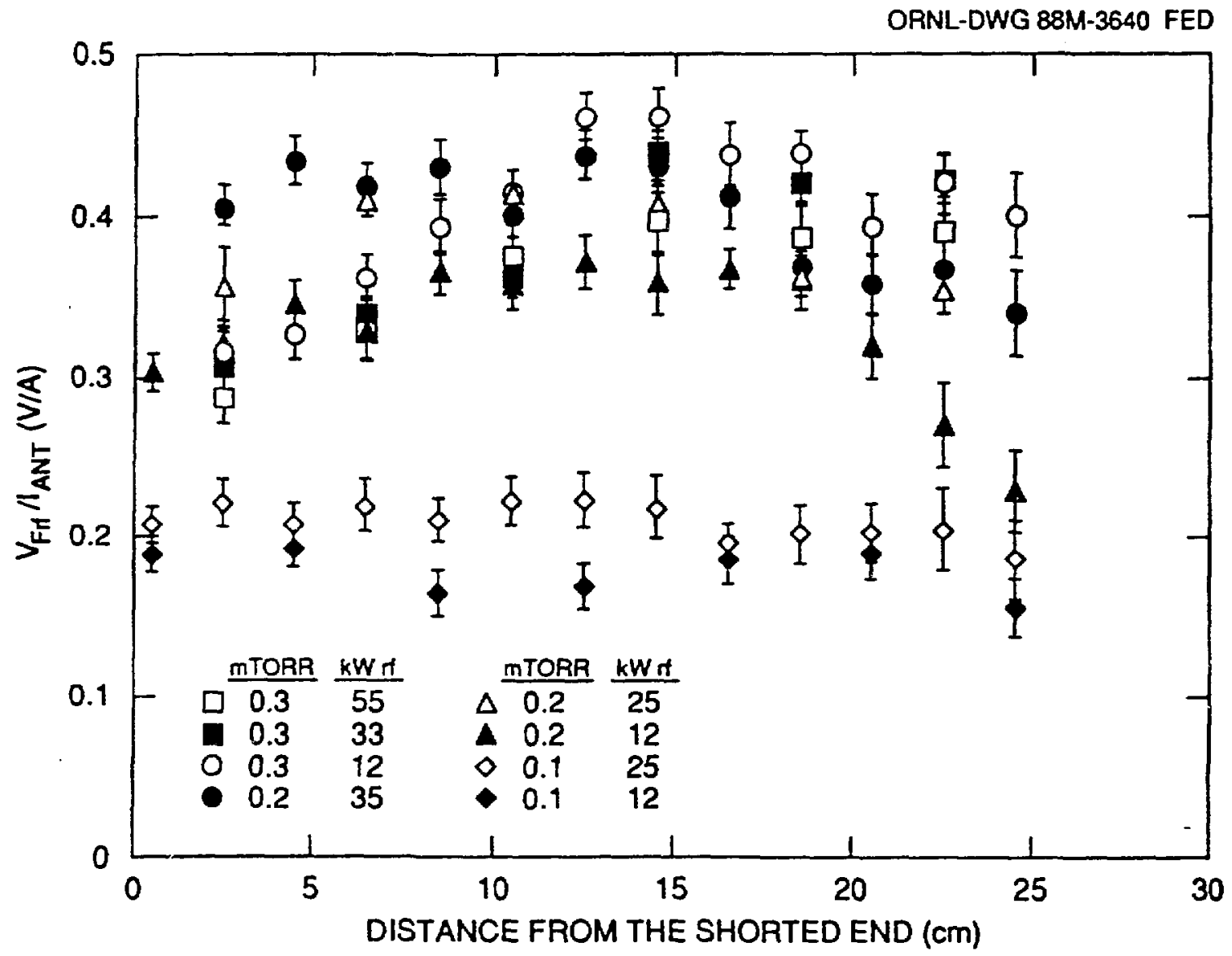

Fig. 2. 
EECTRON TEMPERATURE IN FRONT OF THE ANTENM

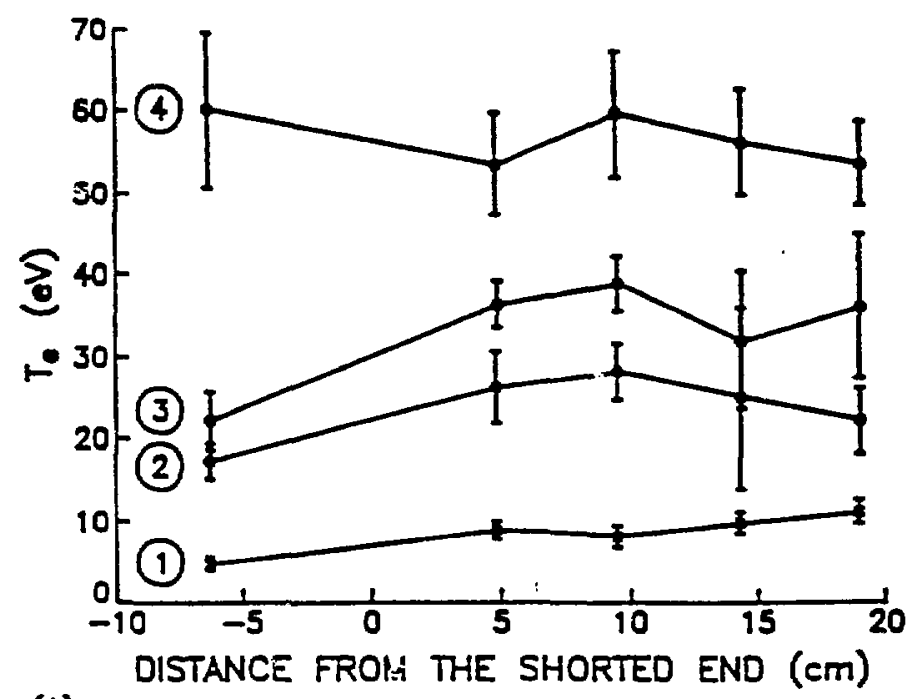

\begin{tabular}{c|c|c} 
& $P_{\mathrm{H}}(\mathrm{KW})$ & $I_{\mathrm{MT}}(\mathrm{A})$ \\
\hline (1) & - & - \\
(2) & 2.5 & 110 \\
(3) & 2.5 & 133 \\
(4) & 26 & 390
\end{tabular}

AVERAGE PLASMA POTENTUL IN FRONT OF THE ANTENMA

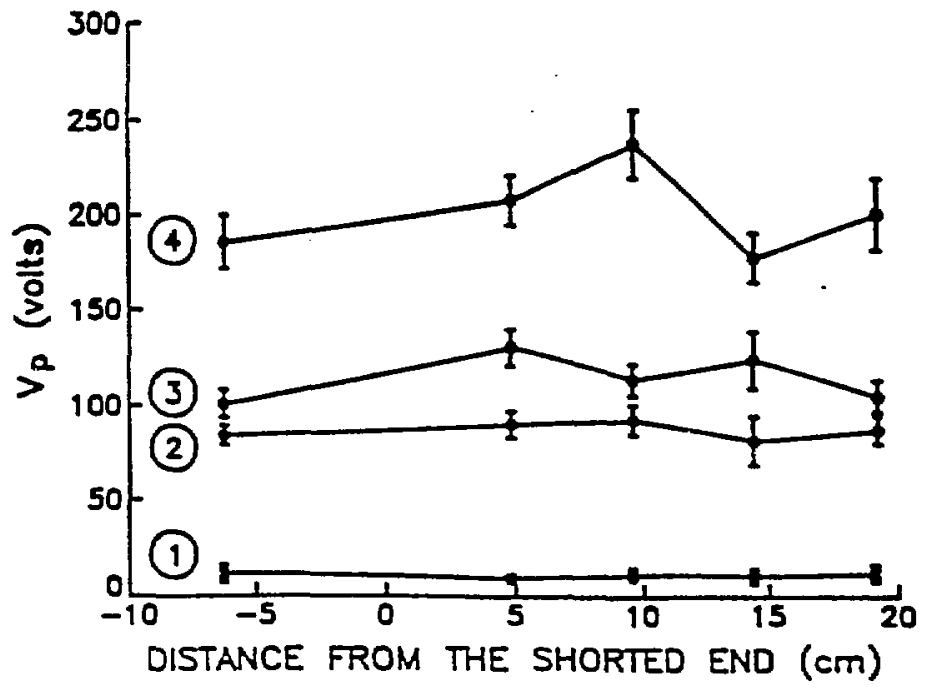

Fig. 3. 


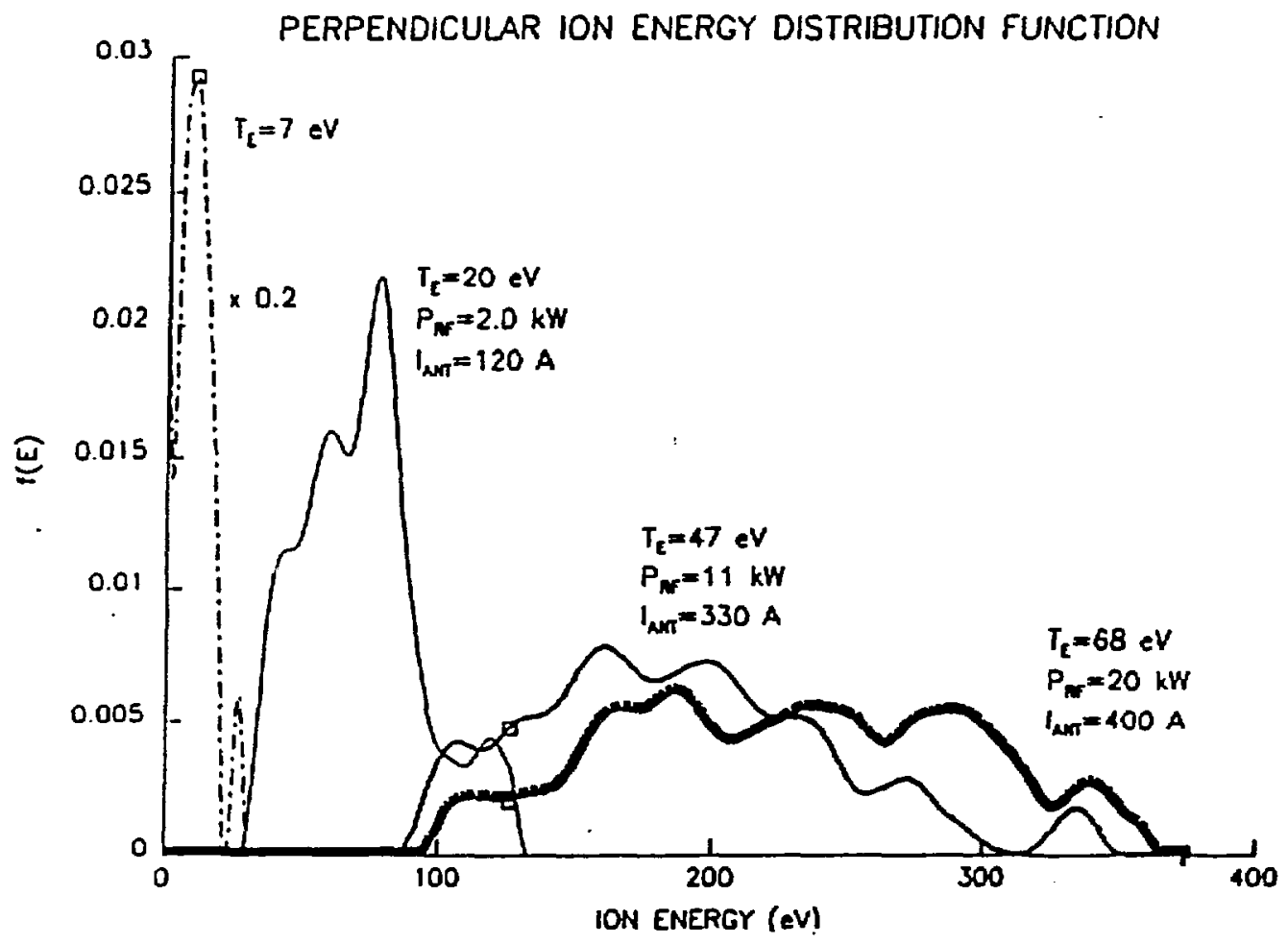

Fig. 4. 